\title{
PET Flasher: A machine language subroutine for timing visual displays and response latencies
}

\author{
PHILIP M. MERIKLE, JIM CHEESMAN, and JOHN BRAY \\ University of Waterloo, Waterloo, Ontario N2L 3G1, Canada
}

\begin{abstract}
PET Flasher presents a one-line stimulus display at any location on a PET/CBM (Commodore Business Machines) screen and measures reaction time from display onset. Display duration is accurately controlled in $16.7-\mathrm{msec}$ steps, and reaction time measurement is accurate within \pm 1 msec. PET Flasher is easily incorporated within any PET/CBM BASIC program, since as a subroutine, it is called only when precise timing operations are required.
\end{abstract}

A serious problem encountered by anyone who attempts to use a PET/CBM microcomputer to present brief visual displays or to time response latencies is that programs written in BASIC cannot provide accurate timing. The timing accuracy possible with BASIC programs is limited by two factors. First, the most precise clock available within a BASIC program is the jiffy clock, which increments once every $16.7 \mathrm{msec}$. Second, even if the jiffy clock is considered to provide sufficient precision for some experimental applications, certain characteristics of the PET/CBM operating system make it impossible to use the jiffy clock within a BASIC program to provide consistent control of display duration. For any BASIC program involving the presentation of a visual display, the timing accuracy is considerably less than $\pm 16.7 \mathrm{msec}$, and more important, the accuracy of any such timing operation programmed in BASIC varies in an inconsistent and indeterminant manner from trial to trial (Lincoln \& Lane, 1980). The way to overcome these limitations of PET/CBM BASIC programs is to measure all critical temporal intervals by a machine language subroutine.

PET Flasher represents one method for accurately timing visual displays and response latencies to these displays. The subroutine is written for a PET/CBM 2001 microcomputer with Revision $3 \mathrm{ROMs}$, and according to available memory maps (Osbourne \& Donahue, 1980), it should run with slight modification on older PETs containing Revision 2 ROMs. ${ }^{1}$ The major characteristics of PET Flasher are as follows: (1) A one-line stimulus display, consisting of 1-31 characters, is presented at the center of the screen; (2) all characters available on the PET/CBM keyboard may be displayed, including mixed upper- and lowercase letters; (3) display duration

Development of this program was supported by Grant APA231 from the Natural Sciences and Engineering Research Council Canada to P. M. Merikle. Requests for reprints should be addressed to Philip M. Merikle, Department of Psychology, University of Waterloo, Waterloo, Ontario N2L 3G1, Canada. can vary from $16.7 \mathrm{msec}$ to $4,250 \mathrm{msec}$; (4) the time from display onset to the closure of a switch connected to the parallel user port is measured with $\pm 1-\mathrm{msec}$ accuracy to a maximum response latency of $16.7 \mathrm{sec}$; (5) switch closure terminates the display, if it occurs prior to the specified display duration; and (6) multiple switches may be connected to the parallel user port, and the program records which switch was closed.

PET Flasher has two distinctive characteristics, which are illustrated in the assembled machine code shown in Figure 1. First, millisecond timing accuracy is achieved through the use of the PET/CBM microsecond timer (T2) located at \$E848 and \$E849. However, since these counters have a $65.5-\mathrm{msec}$ limit, an additional counter (\$03D5) is incremented via the interrupt system whenever T2 times out (see DeJong, 1979). In this way, it is possible to measure response latencies up to a maximum of $16.7 \mathrm{sec}$. The second distinctive characteristic concerns the method used to coordinate presentation of the visual displays with the CRT sweep. Since the rollover of the PET/CBM jiffy clock $(\$ 8 \mathrm{~F})$ is synchronized with the beginning of the CRT sweep, the program waits for the jiffy clock to roll over and then sets a microsecond counter (T1) to time out every $16.7 \mathrm{msec}$, which is the time required for each sweep of the CRT screen. Thus, display duration is controlled in steps of $16.7 \mathrm{msec}$, and this is the maximum possible resolution when a standard CRT is used.

These two characteristics of PET Flasher distinguish it from previous proposals for obtaining accurate timing and display-CRT coordination with microcomputers. Since PET Flasher utilizes the microsecond timer within the 6522 versatile interface adapter, software timing subroutines, such as those proposed by Price (1979), are not required. In addition, the hardware modification suggested by Reed (1979) to achieve display-CRT coordination is not necessary, since PET Flasher synchronizes display presentation with the rollover of the jiffy clock. These distinguishing characteristics of PET 


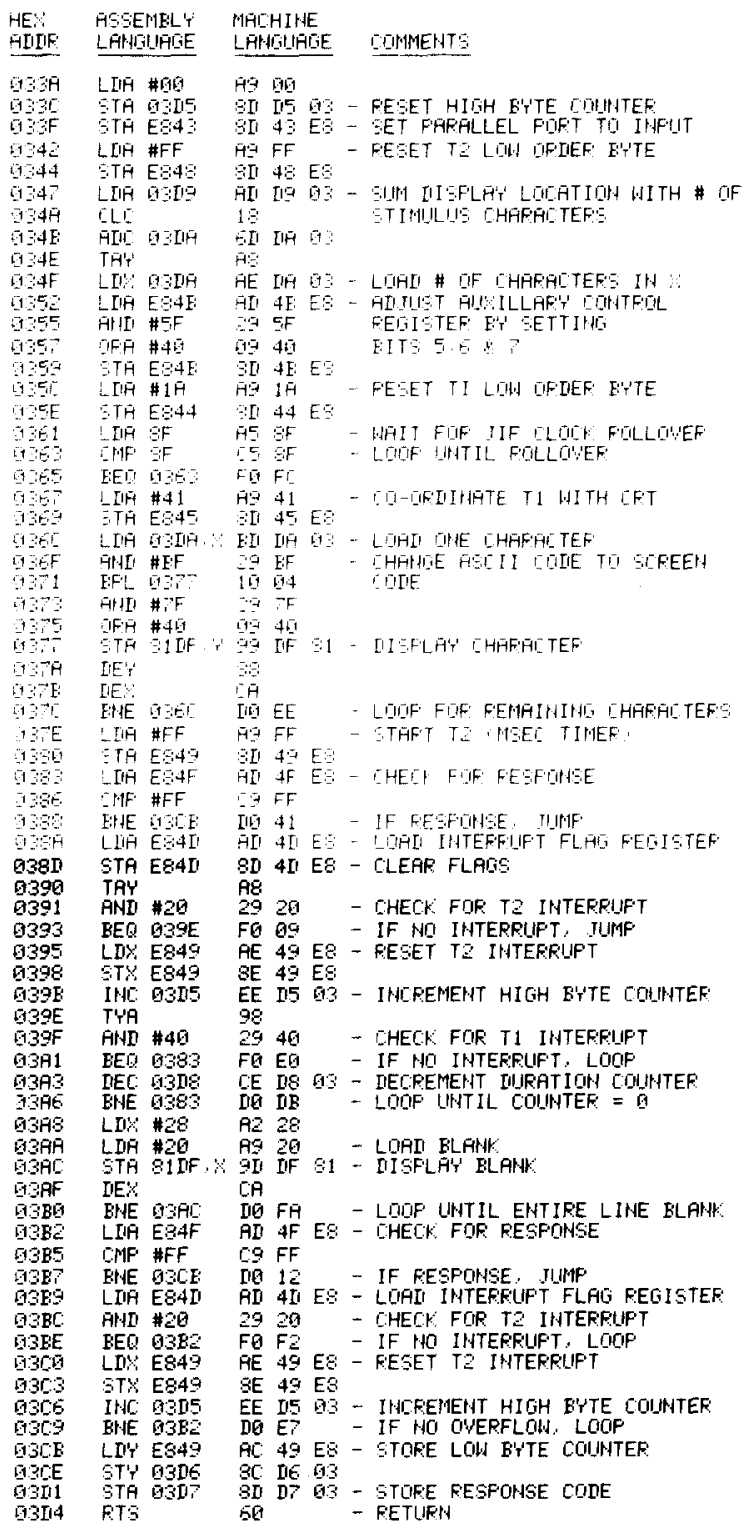

Figure 1. Assembled machine code for PET Flasher.

Flasher have a price, however, in that by using unique characteristics of PET/CBM microcomputers, PET Flasher works only on Commodore Business Machines microprocessors.

An example of how PET Flasher can be used within a BASIC program is shown in Figure 2. Initially, the program READs the machine code from DATA statements and POKEs it into the second-cassette buffer, which is a protected area. Display location (985) specifies the number of spaces from the left side of the screen to the leftmost character in a display, and display duration (984) is specified in multiples of $16.7 \mathrm{msec}$. Before a stimulus display is presented, the display buffer, which occupies the top 31 locations in the secondcassette buffer (987-1017), is loaded with the ASCII code for each character in the display. Following presentation of the fixation point, a switch connected to the parallel user port must be closed (Line 310) and opened (Line 320) before PET Flasher is called (SYS 826). Since PET Flasher initiates display presentation prior to checking for a response, any responses that may occur prior to display onset have no effect. Once a response does occur, control returns to the BASIC program, which first clears the screen and then computes the reaction time from display onset. If no response occurs within $16.7 \mathrm{sec}$ after display onset, control returns automatically to the BASIC program and the calculated reaction time is $0 \mathrm{msec}$.

The response keys necessary to use PET Flasher are connected to the parallel user port. Any reasonable quality SPST switch may be used, and each switch simply grounds one of the input/output lines (PA0 to PA7). The exact pin connections are given in the CBM User Manual (Commodore Business Machines, 1979). Since there are eight input/output lines, up to eight different switches may be used. Closure of each switch produces a unique code, and these codes are accessible

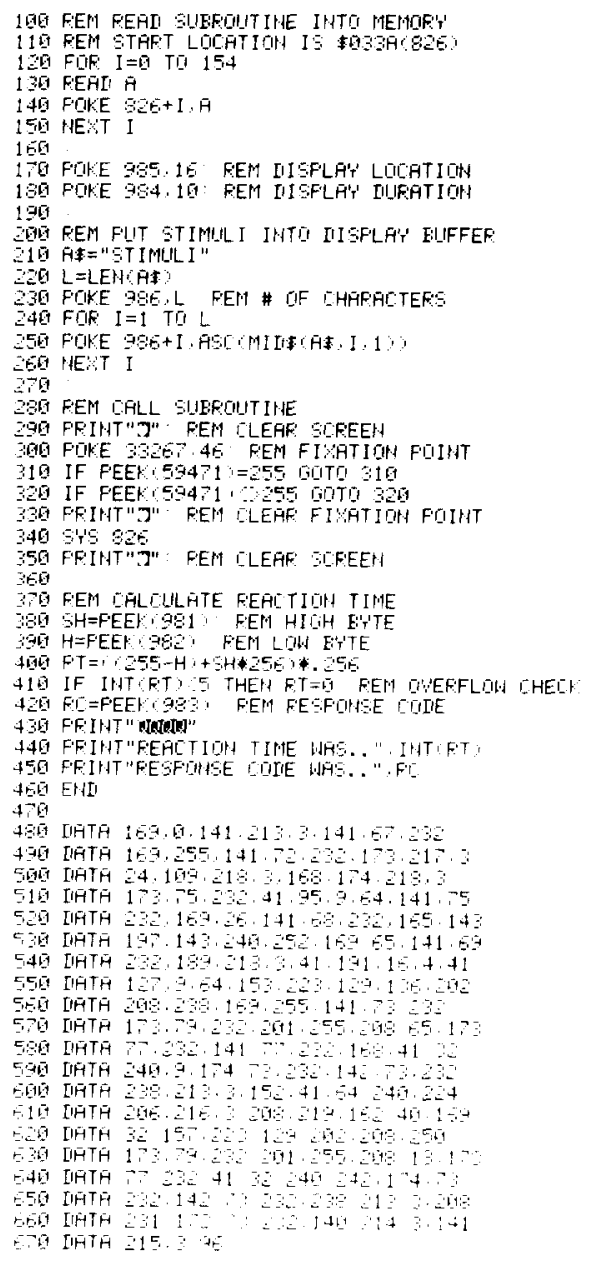

Figure 2. A BASIC program that implements PET Flasher. 
Table 1

Screen Memory Addresses for Each Screen Line

\begin{tabular}{|c|c|c|c|c|}
\hline \multirow[b]{2}{*}{ Line } & \multicolumn{2}{|c|}{ Address } & \multicolumn{2}{|c|}{ Byte } \\
\hline & Hexadecimal & Decimal & Low & High \\
\hline 01 & 7FFF & 32767 & 255 & 127 \\
\hline 02 & 8027 & 32807 & 039 & 128 \\
\hline 03 & $804 \mathrm{~F}$ & 32847 & 079 & 128 \\
\hline 04 & 8077 & 32887 & 119 & 128 \\
\hline 05 & $809 \mathrm{~F}$ & 32927 & 159 & 128 \\
\hline 06 & $80 C 7$ & 32967 & 199 & 128 \\
\hline 07 & $80 \mathrm{EF}$ & 33007 & 239 & 128 \\
\hline 08 & 8117 & 33047 & 023 & 129 \\
\hline 09 & $813 \mathrm{~F}$ & 33087 & 063 & 129 \\
\hline 10 & 8167 & 33127 & 103 & 129 \\
\hline 11 & $818 \mathrm{~F}$ & 33167 & 143 & 129 \\
\hline 12 & $81 \mathrm{~B} 7$ & 33207 & 183 & 129 \\
\hline 13 & $81 \mathrm{DF}$ & 33247 & 223 & 129 \\
\hline 14 & 8207 & 33287 & 007 & 130 \\
\hline 15 & $822 \mathrm{~F}$ & 33327 & 047 & 130 \\
\hline 16 & 8257 & 33367 & 087 & 130 \\
\hline 17 & $827 \mathrm{~F}$ & 33407 & 127 & 130 \\
\hline 18 & $82 \mathrm{~A} 7$ & 33447 & 167 & 130 \\
\hline 19 & $82 \mathrm{CF}$ & 33487 & 207 & 130 \\
\hline 20 & $82 \mathrm{~F} 7$ & 33527 & 247 & 130 \\
\hline 21 & $831 \mathrm{~F}$ & 33567 & 031 & 131 \\
\hline 22 & 8347 & 33607 & 071 & 131 \\
\hline 23 & $836 \mathrm{~F}$ & 33647 & 111 & 131 \\
\hline 24 & 8397 & 33687 & 151 & 131 \\
\hline 25 & $83 \mathrm{BF}$ & 33727 & 191 & 131 \\
\hline
\end{tabular}

in BASIC by PEEKing Location 59471. When no switch is closed, the decimal code at Location 59471 is 255. Switch debouncing is not necessary.

PET Flasher has been tested against an external time base. We have verified that displays are presented for the specified number of CRT sweeps and that reaction times from display onset are accurate within $\pm 1 \mathrm{msec}$. However, when PET Flasher presents a stimulus display at the center of the CRT screen (Line 13), as is done by the version described in this article, there is a constant 8-msec discrepancy between the reaction times measured by PET Flasher and the same reaction times measured by an external timer. This occurs because PET Flasher times from the beginning of the screen sweep, whereas an external timer cannot be activated until the sweep reaches the center of the CRT screen and the stimulus display is presented. This constant error is easily corrected by subtracting $8 \mathrm{msec}$ from the calculated reaction times.

With one rather straightforward change, PET Flasher can be modified to present the one-line display at any screen location. All that is required are new values in the locations used by PET Flasher to select a particular line in screen memory. These values are shown in Table 1, which gives the high and low byte-decimal equivalents corresponding to each of the 25 screen lines. Since PET Flasher stores the low byte values in Locations 888 and 941 and stores the high byte values in Locations 889 and 942, display location can be changed by simply POKEing the appropriate low and high byte values into these locations prior to calling the subroutine. For example, to present a display at Line 6 on the screen, Line 270 in the BASIC program requires the following statement sequence: POKE 888, 199: POKE 889, 128: POKE, 941, 199: POKE 942, 128. If these or similar POKE statements are not included in the BASIC program, then PET Flasher, by default, presents the display on Line 13 of the screen.

The fixation point can also be located anywhere on the screen, since any screen location (32768 to 33767) may be specified in the POKE statement on Line 300 of the BASIC program in Figure 2. In addition, any character in the PET/CBM character set may be used for fixation by POKEing the location specified in Line 300 with the PET/CBM decimal code for the selected character.

PET Flasher meets our need to use PET/CBM microcomputers to measure reaction times to visual displays with millisecond accuracy. In addition, since PET Flasher is easily incorporated within any BASIC program, it has proved useful in a variety of experimental contexts requiring accurately timed stimulus displays and reaction times to these displays.

\section{REFERENCES}

Commodore Business Machines. CBM user manual. Santa Clara, Calif: Author, 1979.

DEJong, M. L. 6522 timing and counting techniques. MICROThe 6502 Journal, 1979, 17, 27-39.

Lincoln, C. E., \& Lane, D. M. Reaction time measurement errors resulting from the use of CRT displays. Behavior Research Methods \& Instrumentation, 1980, 12, 55-57.

Osbourne, A., \& Donahue, C. S. PET/CBM personal computer guide (2nd ed.). Berkeley: Osbourne/McGraw-Hill, 1980.

Price, J. M. Software timing for 6500 series microcomputers. Behavior Research Methods \& Instrumentation, 1979, 11, 568571.

Reed, A. V. Microcomputer display timing: Problems and solutions. Behavior Research Methods \& Instrumentation, 1979, 11, 572-576.

\section{NOTE}

1. In Revision 2 ROMs, the jiffy clock is located on Page 2 rather than Page 0 . As a result, two additional instructions must be added to the subroutine, and the high and low byte counters must be relocated. These modifications are available upon request.

(Received for publication September 8, 1981; revision accepted January 13, 1982.) 